By IO. Io nothing was left except the arch, and between ro.ro and I I that also vanished.

The stars could be seen distinctly through the aurora. When the light was at the brightest I could see the figures and hands of a lange watch, but could not distinguish the figures one from another. Thermometer $30^{\circ} 5 \mathrm{~F}$.; Barometer $29^{\circ} 69$ inches.

Pixholme, Dorking, Surrey J. E. H. GORDON

\section{Structure of Lepidodendron}

PROFESSOR DYer has already discovered one of the many new facts with which he has yet to become familiar, and hastens, in a straightforward manner, to acknowledge the circumstance; but I must again remind him that this, along with many other facts, was described in No. 129 of the Proceedings of the Royal Society. Professor Dyer further says: "Suppose the transverse septa separating these cells absorbed, as probably cuentually they cuould haze leen, and the rows of cells become scalariform vessels." But I can assure him, as a question of fact, that these cells do not become so changed; consequently his conclusion that the central cells and the investing vessels are but parts of "one central structure" becomes negatived. The separation of these two structures increases with age instead of diminishing.

$$
\text { W. C. Wilt.ramson }
$$

\section{Encke's Comet}

IT may interest those who possess small telescopes to know that this comet is now within the range of instruments of moderate apertures. On November Io I had a very satisfactory view of it, with a $4^{\prime \prime}$ equatorial by Cooke; no signs of a nucleus were observed, but there appeared to be a slight condensation of light on the following side of the comet.

\section{Bedford, Nov. Ir}

\section{The Science and Art Department}

IN your last number there appears a letter signed "Henry Uhlgren," which, among other interesting statements, contains the following: Referring to Mr. Forster's statement in the Ilouse of Commons that there was no foundation for the report that "the Examiners after having made their reports had the papers returned to them, with an instruction to reduce the number of successful candidates, as an intination had been given by a right hon. gentleman that the amount of the Grant due upon thosc papers must be reduced 20,000l.," Mr. Uhlgren states: "But previous to that a provincial local secretary, hearing the rumour, wrote to ask the Department if it were true, and received a reply saying it was true, and that instead of the amount being $20,0 \mathrm{col}$. it was $40,000 \%$. (the Department's letter can be produced.)" Premising that the amount of the whole vote for payments to teachers on results in science (which was to be reduced by $40,000 l$.) was $26,000 l$, may I ask for the prorluction or publication of this extraordinary official letter?

\section{ECONOMICAL ALIMENTATION}

$\mathrm{I}^{\mathrm{N}}$ glancing over the recent issues of the Comptes Rendus, one cannot but fail to be struck with the practical importance of many of the communications contained therein, a large proportion of which bear special reference to the Siege of Paris. In nearly every branch of science there is some endeavour made to supplement and improve our knowledge in matters such as were then of the greatest importance, and the members of the Académie have come forward eagerly to aid, by advice and precept, in overcoming the misery of a prolonged siege. Unfortunately, but little could be done, even by such men as Fremy, Dumas, Chevreul, and others, against the insuperable difficulties which presented themselves; but nevertheless. Paris owes much to her men of science who contributed many services of value, at a time when these were most needed. The manufacture and employment of nitro-glycerine in mines and shells, were successfully accomplished at a crisis when the stock of gunpowder was running terribly short, and the supply of some other reliable explosive was rendered imperative. Hitherto nitro-glycerine had been regarded as a most dangerous combustible, liable to explode at the slightest concussion, and yet we hear of its employment in shells against the Prussians, thundered forth from guns of the heaviest calibre, without one single instance of its premature explosion being recorded. Again the question of ballooning, although not perhaps very far advanced by the deliberations of the Academie, has, at any rate, been more satisfactorily solved than at any previous period, and Paris has been certainly the first to employ these frail and romantic contrivances in a practical every-day manner, and thus to render the words, "par ballon monte" familiar to the ear as a household phrase. In matters of surgery, as in those of a sanitary nature, sound advice was not wanting, and even the abstract calling of the soldier, - the philosophy of his manner of fighting-formed the theme of much scientific discussion.

But the most interesting, perhaps, of all the subjects with which the Academie des S'ciences busied itself, was that of seeking an economical means of alimeniation for the inhabitants of Paris during the siege. Given certain limited sources of supply, a fixed amount of suitable organic matter, and the problem was how to use the same to the fullest and most profitable degree. Of sheep and oxen there was but an exceedingly limited provision in proportion to the very populous state of the city, and although corn and wine were said to be in abundance, there is no doubt the authorities were from the first sorely troubled by the vague estimates that were published of these comestibles.

As a suitable manner of economising corn, M. Gauldrée called attention to the method in vogue among the Romans of parching and bruising the grains, which in this state may be made to yield an excellent and highly nutritious soup or porridge. The corn is carefully sifted by hand, browned without charring, until it breaks when taken between the teeth, and then ground in any available mill; it is mixed with cold water, boiled for thirty minutes, and seasoned as desired. So economical was this preparation, that at the public kitchens, established in certain quarters of Paris, it was possible to dispense one portion of bouillie romaine together with a small modicum of wine for the amount of five centimes.

A proposition to manufacture artificial milk, brought forward by M. Gaudin, seems worthy of some notice. That gentleman estimated that 500,000 litres per day of milk could be prepared in Paris at an exceedingly trifling cost, which should have all the nutritious qualities of good milk, and which should, besides, be neither unpleasant of taste or smell. An emulsion at a very high temperature is made of bouillon de viande prepared from bones, fat, and gelatine, and when cold, a product is obtained resembling in taste stale milk of a cheesy flavour; the components of ordinary milk are all present, the gelatine representing the casein; fat, the butter ; and sugar, the sugar of milk. For admixture with coffee, chocolate, soup, \&c., the milk is said to be by no means disagreeable.

Many propositions were brought forward to economise the blood from the abattoir, the plan suggested by M. Gaultier of mixing it with flour in the manufacture of bread being perhaps the best and simplest, as the fibrine and albumen, so rich in nitrogen--of which the alimentary properties are well known-are in this way utilised to the highest degree. Less inviting is the proposal of M. Fud to consume he carcases of animals that died of typlus, rhinderpest, and other diseases, the flesh in these instances being, so asserts M. Fud, capable of use as food, if only cooked in a suitable manner.

More important, however, than all, is M. Fremy's attempt to bring forward osseine as an article of food. Osseine is essentially different from gelatine, which has recently been asserted by chemists-erroneously, so $M$ : Fremy thinks - to be not only unnutritious, but positively injurious to the human system. Leaving, however, the question of gelatine on one side, M. Fremy procteis to advance the qualifications of osseine as an alimentary substance. Although gelatine and osseine are isomeric, in the same way as starch and dextrine are isomeric, they 
have not the same properties. Gelatine, unlike osseine, does not exist in organism, but is produced by chemical transformation resulting from the action of water and heat upon the bony tissue; gelatine, moreover, is completely soluble in water, while osseine is not so. For these reasons the two substances would doubtless be different in their alimentary capacities, and deductions drawn from the influence of one upon the human system ought not in any way to prejudice the other. Of course, says M. Fremy, osseine cannot be expected to fulfil the same duty as a complete aliment; such, for instance, as bread, or meat, but nust be employed in conjunction with some other suitable material. In the same way gluten, which is simply flour freed from starch, oil, and soluble substances, would alone be powerless to support life and bealth. If regarded in the same light as fibrine, casein, and albumen, and associated with other bodies, osseine would be found a valuable aliment. White meat, calf's head, neatsfoot, $\& c$, contain much bony tissue, and their nutritious qualities are incontestable.

Of this osseine, then, bones are said to contain 35 per cent, the mode of separation being simply to slice the bone very thinly, and to treat the same with dilute hydrochloric acid; hard white bones, free from fat, are most suitable, and some care and attention in manipulation is of course necessary, so that the product may be perfectly sweet and free from any taint or unpleasant odour. For if disgust is once aroused against this kind of food, as indeed against any other for that matter, no amount of pushing or puffing can force it into the public market. Should, therefore, any trace of acid be perceptible after preparation of the osseine, it is recommended that the product be treated with an alkali of some lind, for example, lime or carbonate of soda, but this must obviously be done with due care and discretion. The cost of this aliment is about one franc per pound, whereas gelatine of good quality costs from four to five francs.

As regards the best method of cooking or curing, $M$. Fremy recommends the swelling of the mass with hot water, and then boiling for about an hour, when the tissue becomes soft and pliable; it may be seasoned in the cooking, or may be allowed to cool and then kept for thirty-six hours in brine. If eaten warm with admixture of some fat and vegetables the osseine is decidedly palatable. Owing to its large constituent of nitrogen it is extremely nutritious, and, furthermore, fornis a comestible not liable to become putrid.

It is right to mention that on some of the points enumerated by M. Fremy, exception is taken by M. Dumas and others, who are not so confident of the real value of osseine as an alimentary substance, those gentlemen maintaining the injurious nature of gelatine; $M$. Chevreul, however, confirms to some extent M. Fremy, and states that osseine is decidedly more nutritious than gelatine.

Other measures for improving the alimentation of Paris were taken during the siege, but these for the most part present little novelty. Mr. Wilson's plan for salting the carcases intact, and thus preserving the meat in an almost fresh condition, was resorted to, that gentleman bringing his personal staff from Ireland to afford assistance just at the instant of closing the gates of the metropolis. The assistance of M. Georges, whose plan of preserving meat is both original and peculiar, was likewise cbtained ; this invention, which has been practised it is saidwith much success in America, is adapted more particularly for the curing of mutton rather than beef, and consists in treating the meat in a bath acidified with hydrochloric acid, and afterwards in a solution of sulphite of soda. In this condition, after further sprinkling with sulphite of soda, the flesh is packed in tins and soldered down: the sulphite of soda acting upon the hydrochloric acid gives rise to sea salt and sulphurous acid, thus ensuring the perfect preservation of the meat.

H. B. P.

\section{THE TEMPERATURE PRODUCED BY SOLAR RADIATION}

SIR ISAAC NEWTON determined the intensity of solar radiation by observing the increment of temperature of dry earth on being exposed to the sun. In the latitude of London at midsummer, dry earth acquires a temperature of $150^{\circ}$ in the sun at noon and $85^{\circ}$ in the shade, difference about $65^{\circ} \mathrm{Fah}$. This difference Sir Isaac Newton regarded as a true index of the intensity of solar radiation; hence his celebrated demonstration proving that the comet of 1680 was subjected to a temperature 7,000 times higher than that of boiling water $\left(212^{\circ} \times 7,000=1,484,000^{\circ} \mathrm{Fah}.\right) .^{*}$ The comet when in its perikelion being within one-third part of the radius of the sun from his surface, we have to add the diminution of temperature, 044 , attending the dispersion of the rays in passing through the solar atmosphere and the remainder of the stated distance from the sun. Accordingly, the demonstration showing that the comet of 1680 was subjected to a temperature 7,000 times higher than that of boiling water, establishes a solar temperature exceeding $2,640,000^{\circ}$; and if we add 0.21 for the retardation of the rays in traversing the terrestrial atmosphere, it will be found that the temperature deduced from the experiments with incandescent radiators, and our actinometer observations, differs scarcely $\frac{1}{5}$ from that roughly estimated by the author of the "Principia." In order to comprehend fully the merits of the method of determining solar intensity conceived by his master mind, let us imagine an extended surface of dry earth, one half of which is shaded, the other half being exposed to the sun. Dry earth being a powerfil absorbent and radiator, and at the same time a bad conductor, the central portion of the supposed surface evidently cannot suffer any loss of heat by lateral radiation; while the non-conducting property of the material prevents loss by conduction laterally or downwards. Consequently, no reduction of temperature can take piace excepting by radiation in the direction of the source of the heat. Removing the shade, during an investigation, it will be found that, notwithstanding the uninterrupted radiation of the exposed substance upwards, the intensity will gradually increase until an additional temperature of about $65^{\circ}$ Fah. has been acquired. Indisputably, this increase of temperature is due to unaided solar radiation. Evidently the accidental interference of currents of air need not be considered. Besides, if the dry earth is confined within a vacuum, such interference rnay be entirely obviated. It is scarcely necessary to point out that the generally-adopted mode of measuring the sun's radiant heat by thermometers, is in direct opposition to the principle involved in the method under consideration. 'The meteorologist, in place of preventing the bulb from radiating in all directions and guarding against loss of heat by convection, puts his thermometer on the grass, or suspends it on a post, one half of the convex area of the bulb receiving the sun's radiant heat, while the other half is permitted to radiate freely, the whole being exposed to the radiation from surrounding objects and to the refrigerating influence of accidental currents of air, in addition to the permanent current produced by the ascending heated column above the bulb. This explains the cause of the perplexing discrepancies in meteorological records. The extent of the diminution of intensity of solar radiation occasioned by cold air acting on the bulb, and by the latter radiating freely in all directions, is demonstrated in the most conclusive manner by the result of observations made with the instrument described by Père Secchi in

* Sir Isaac Newton has been criticised for comparing the temperature to scription," it is said in " " term of comparison indeed of a very vague de being correct, since the lemonstration fronomy. This criticism is far from term red-hot, viz, a temperature reference to red-heat, exceeded "two thousand times" 3 " 5 times water. The tended to furnish some a ceeded "two thousand times," was evidently intemperature involved in the computation.
the inconceivably high degree of 